\title{
Changes in Chemical and Physical Properties of Pine Tree Substrate and Pine Bark During Long-term Nursery Crop Production
}

\author{
Brian E. Jackson ${ }^{1,3}$ and Robert D. Wright ${ }^{2}$ \\ Department of Horticulture, Virginia Polytechnic Institute and State \\ University, 301 Saunders Hall, Blacksburg, VA 24061
}

John R. Seiler ${ }^{2}$

Department of Forestry, Virginia Polytechnic Institute and State University, Blacksburg, VA 24061

Additional index words. $\mathrm{CO}_{2}$ efflux, container substrate, loblolly pine, Pinus taeda L., pine chips, potting media, wood fiber

\begin{abstract}
The objective of this study was to evaluate a pine tree substrate (PTS) for decomposition, changes in physical and chemical properties, and substrate carbon dioxide $\left(\mathrm{CO}_{2}\right)$ efflux (microbial activity) during a long-term production cycle under outdoor nursery conditions. Substrates used in this study were PTS constructed using a 4.76-mm hammer mill screen and aged pine bark (PB). Plastic nursery containers were filled with each substrate and amended with either 4.2 or $8.4 \mathrm{~kg} \cdot \mathrm{m}^{-3}$ Osmocote Plus fertilizer and planted with Cotoneaster horizontalis or left fallow. Substrate solution chemical properties and nutrient concentrations were determined each month during the summers of 2006 and 2007 in addition to measuring substrate $\mathrm{CO}_{2}$ efflux ( $\mu \mathrm{mol}$ $\mathrm{CO}_{2} / \mathrm{m}^{-2} \cdot \mathrm{s}^{-1}$ ) as an assessment of microbial activity. Substrate breakdown (decomposition) was determined with particle size analysis and physical property determination on substrates at the conclusion of the study ( 70 weeks). Substrate solution $\mathrm{pH}$ was higher in PTS than in PB at both fertilizer rates in 2006, but pH levels decreased over time and were lower in PTS at both fertilizer rates in 2007. Substrate solution electrical conductivity levels, nitrate, phosphorus, and potassium concentrations were all generally higher in PB than in PTS at both fertilizer rates through both years. Pine tree substrate decomposition was higher when plants were present in the containers [evident by an increase in fine substrate particles (less than $0.5 \mathrm{~mm}$ ) after 70 weeks], but breakdown was equal at both fertilizer rates. Shrinkage of PTS in the presence of plants was equal to the shrinkage observed in PB with plants, but shrinkage was higher in fallow PTS containers than PTS with plants. Substrate air apace (AS) was highest in PTS and container capacity (CC) was equal in PB and PTS at potting. Substrate AS decreased and CC increased in both substrates after 70 weeks but remained in acceptable ranges for container substrates. Substrate $\mathrm{CO}_{2}$ efflux rates were higher in PTS compared with PB at both fertilizer rates indicating higher microbial activity, thereby increasing the potential for nutrient immobilization and substrate breakdown. This work provides evidence that PTS decomposition is unaffected by fertilizer rate and that substrate shrinkage in containers with plants is similar to PB after two growing seasons ( 70 weeks), which addresses two major concerns about the use and performance of PTS for long-term nursery crop production. This work also shows that the higher microbial activity in PTS increases the potential of microbial nutrient immobilization, which is likely the reason for the lower substrate nutrient levels reported for PTS compared with PB over 70 weeks.
\end{abstract}

Received for publication 2 Dec. 2008. Accepted for publication 24 Mar. 2009.

This research was funded in part by the American Floral Endowment, Virginia Agricultural Council, the Virginia Nursery and Landscape Association, and the Virginia Tobacco Commission.

Technical assistance of Joyce Shelton is gratefully acknowledged.

Use of trade names does not imply endorsement of the products named nor criticism of similar ones not mentioned.

The cost of publishing this paper was defrayed in part by payment of page charges.

${ }^{1}$ Former Graduate Research Assistant.

${ }^{2}$ Professor.

${ }^{3}$ To whom reprint requests should be addressed; e-mail brian_jackson@ncsu.edu.
Beginning in the early 1970 s, the search for organic soilless substrates for container production has been an important horticultural research topic with the introduction of hardwood and softwood barks as the primary component in nursery container substrates (Aaron, 1982; Hoitink and Poole, 1979). Recently, supplies of pine bark (PB) in many areas across the southeastern states have been erratic. Reduced availability and higher costs have been driven by the reduced supply resulting from decreased pine tree harvesting for the paper and timber industry and also by the use of PB as a fuel source, in retail potting media, and as landscape mulches.
Wood-based substrates have been some of the more heavily researched and successful alternative materials evaluated in recent decades. Successful growth of woody nursery crops in wood substrates have been reported using several wood materials, including cedar chips (Brown and Emino, 1981), pruning and forest residue wastes (Riviere and Milhau, 1983), commercial wood fiber substrates including Cultifibre ${ }^{\circledR}$, Hortifibre ${ }^{\circledR}$, and Toresa $^{\circledR}$ (Bohne, 2004; Lemaire et al., 1989), and hardwood chips from ground whole oak and elm trees (Kenna and Whitcomb, 1985). Laiche and Nash (1986) were the first in the United States to produce a pine tree substrate (PTS) composed of a mixture of PB and fresh loblolly pine wood and a second PTS derived from whole pine trees (needles, limbs, bark, and wood). They reported that plant growth of several woody plants to be highest in $100 \%$ PB compared with the two PTSs and that additional work was needed before pine wood could be used as a container substrate. Two decades later, Wright and Browder (2005) demonstrated that woody and herbaceous plants could be grown in a $100 \%$ PTS produced from debarked loblolly pine logs. Wright et al. (2006) and Jackson (2008) also evaluated the growth of numerous woody nursery species in a PTS produced from ground pine logs (including the bark; $\approx 90 \%$ wood and $10 \%$ bark) compared with $100 \%$ PB. Fain et al. (2008a, 2008b) manufactured a PTS by chipping and grinding freshly harvested 8- to 10-year-old pine trees, including the wood, bark, limbs, and needles. They reported that herbaceous plants grown in PTS were smaller than plants grown in $100 \% \mathrm{~PB}$, but that growth index and visual quality of the plants were similar for both substrates. Further work by Boyer (2008) and Boyer et al. (2008) showed that growth of annual bedding plants was comparable to $100 \%$ PB when grown in a pine substrate derived from pine tree byproducts (limbs, needles, bark, cones, and so on) known as clean chip residual that remains after pine trees are harvested for pulp wood.

Container substrates should maintain adequate air space (AS) and container capacity [CC; which is the equivalent to the waterholding capacity (WHC) of a substrate] during crop production so that growing conditions remain favorable for plant growth. Physical properties of substrates considered appropriate for plant growth at planting may change over time in containers as a result of several processes (Allaire-Leung et al., 1999; Lemaire, 1995). Changes include AS reduction as a result of settling and segregation of particles of variable sizes (Bilderback and Lorscheider, 1995), shrinkage of the substrate (Bruckner, 1997), and organic matter decomposition and physical breakdown of particles (Bollen and Glennie, 1961; Nash and Laiche, 1981). Most research on the physical properties of substrates has used peatmoss or $\mathrm{PB}$, the two most commonly used substrates. Current guidelines for nursery container substrates suggest that after irrigation and drainage, substrates should have 
between $10 \%$ and $30 \% \mathrm{AS}, 45 \%$ to $65 \% \mathrm{CC}$, $25 \%$ to $35 \%$ available water, $25 \%$ to $35 \%$ unavailable water, $50 \%$ to $85 \%$ total porosity (TP), and 0.19 to $0.70 \mathrm{~g} \cdot \mathrm{cm}^{-3}$ bulk density (BD; Yeager et al., 2007). As the use of wood substrates increases, further evaluation of their management requirements and physical property characteristics during crop production is needed. Researchers have shown that initial physical properties of PTS can be engineered for optimal characteristics (Saunders et al., 2006; Wright et al., 2008b) for nursery and greenhouse crop production. The acceptable or optimal physical properties were based on initial physical characteristics determined at the time of planting/potting of plant growth trials and provide no indication as to how long PTS retains satisfactory physical properties under long-term production conditions. However, work by Jackson et al. (2008b) reports that PTS has similar (and within the suggested range) physical properties as peat-lite $[80 \%$ peat $/ 20 \%$ perlite $(\mathrm{v} / \mathrm{v})]$ after 14 weeks under fertilized greenhouse conditions.

Shrinkage of wood substrates in containers has been reported to range from $36 \%$ volume loss over 15 months (Fischer et al., 1993 ) to $50 \%$ volume loss over 51 weeks (Meinken and Fischer, 1997) during crop production. The wood substrates used in these reports were wood fiber (so named as a result of their manufacturing process and physical properties) and were derived from a mixture of various tree species; primarily spruce (Picea abies L.). Jackson and Wright (2009) and Jackson et al. (2008a) report no significant visual substrate shrinkage or decomposition of PTS (produced from delimbed pine trees) during a 4-month greenhouse trial and a 1-year nursery crop trial, and Fain et al. (2008b) reported less shrinkage of a PTS (produced from whole pine trees, including limbs and needles) than a peat substrate during a 5-week greenhouse trial. Jackson et al. (2008b) reported similar shrinkage and change in physical properties of PTS under fertilized greenhouse conditions compared with a traditional peat substrate during a 14-week study. The change in physical properties TP, AS, and CC of PTS during long-term nursery crop production have not been reported and need to be addressed before large-scale production and use of this substrate begins. Determination of the changes in substrate physical properties in undisturbed containers over time (during or at the end of crop production) is difficult to measure and rarely reported in the literature as a result of the absence of a generally accepted and official measurement procedure (Bilderback et al., 2005). Determining the physical properties of a substrate (removed from containers after crop production) with the same laboratory method [e.g., North Carolina State University (NCSU) Porometer] used to determine the initial properties (at potting) is used as a comparison of the breakdown and change in properties of substrates over time under production conditions.
Substrate particle size analysis is often determined to make inferences on the physical properties $(\mathrm{AS}, \mathrm{CC}$, pore space, and so on) expected for that substrate (Bilderback et al., 2005). Substrate particle sizes are commonly grouped into three categories/classes: coarse (greater than $2.0 \mathrm{~mm})$, medium $(0.5$ to $2.0 \mathrm{~mm}$ ), and fine (less than $0.5 \mathrm{~mm}$ ) for discussion (Drzal et al., 1999; Richards et al., 1986). Determination of substrate particle analysis before and after crop production could be an estimate of substrate breakdown by evidence of a reduction in large particles and an increase in fine particles, which is known to occur in organic substrates (Bilderback et al., 2005).

The environmental impact of fertilizer applications, especially nitrogen $(\mathrm{N})$ and phosphorus $(\mathrm{P})$, has been of concern to growers and scientists over the years. Environmental contamination from nitrate $\left(\mathrm{NO}_{3}-\mathrm{N}\right)$ and $\mathrm{P}$ has become an important concern of nursery operators in many areas. Nitrate levels greater than $10 \mathrm{ppm}$ in drinking water are considered unsafe for humans (Environmental Protection Agency, 2006), and $\mathrm{PO}_{4}-\mathrm{P}$ often is associated with algal blooms and eutrophication of lakes and ponds (Hart et al., 2004). Although P is considered rather immobile in many mineral soils, it is more readily leached from soilless container substrates (Broschat, 1995; Yeager and Wright, 1982). Nitrate is readily leached from both mineral soils and soilless container substrates (Bugbee and Elliott, 1998; Yeager et al., 1993). Nutrient loss and availability from PTS during crop production has not been reported in previous literature and remains an important issue in light of the higher fertilizer requirements for 100\% PTS (Jackson et al., 2008a; Jackson and Wright, 2009; Wright et al., 2008a) that are required for optimal plant growth. It has since been shown that PTS can be produced with a smaller hammer mill screen $[2.38 \mathrm{~mm}$; resulting in a PTS with higher percentages of fine particles (less than $0.5 \mathrm{~mm}$ )] or amended with $25 \%$ peatmoss to increase its WHC and nutrient retention, thereby increasing plant growth at lower fertilizer rates similar to those used with a peat substrate (Fain et al., 2008b; Jackson et al., 2008b).

In PTS, the need for additional fertilizer is a result of higher microbial activity resulting in increased $\mathrm{N}$ immobilization in wood-based substrates compared with peat or PB (Jackson, 2008). Numerous authors have reported $\mathrm{N}$ immobilization in wood substrates ranging from 10 to $300 \mathrm{mg} \mathrm{N} / \mathrm{L}$ of substrate per week during crop production (Bodman and Sharman, 1993; Handreck, 1992b; Sharman and Bodman, 1991). Methods of estimating or quantifying microbial biomass (e.g., bacteria, fungi, protozoa) include counting the population (by either microscopy or plating on agar), chloroform fumigation, assaying some unique component of biomass such as ATP, extracellular dehydrogenase, or by measuring the metabolic activity [oxygen consumption or carbon dioxide $\left(\mathrm{CO}_{2}\right)$ release] of the population (Blagodatsky et al., 2000; Needelman et al., 2001; Turner and Carlile, 1983).
Carbon dioxide release represents the final stage of oxidation of organic substrates and is the older and still more commonly used method for estimation of microbial activity in soils (Wang et al., 2003). Because root respiration is also a source of $\mathrm{CO}_{2}$ in the soil, it is important to also consider it as a source of $\mathrm{CO}_{2}$ evolution from a soil/substrate in addition to microbial respiration. Soil respiration/ efflux (by plant roots or microbes) is influenced by a number of factors, including soil/ substrate quality and organic matter content, temperature, soil moisture, root biomass, and microbial activity and biomass (Casadesus et al., 2007; Ding et al., 2007; Fog, 1988; Steinweg et al., 2008; Wang et al., 2003).

The estimation of microbial activity could represent a possible strategy to improve fertilizer efficiency of substrates by better predicting fertilizer use and application timing during crop growth (Gagnon and Simard, 1999; Handreck, 1992a). Long-term evaluations of physical, chemical, microbial, and nutritional properties of PTS during crop production have not been investigated; therefore, the objectives of this study were to evaluate substrate solution nutrient concentrations, changes in physical and chemical properties, substrate shrinkage, and biological (microbial) activity in PTS compared with PB during long-term nursery production.

\section{Materials and Methods}

The substrates used in this experiment were PTS and PB. Pine tree substrate was produced from loblolly pine trees $(\approx 30 \mathrm{~cm}$ basal diameter) that were harvested at ground level and delimbed on 14 Apr. 2006 in Warsaw, VA. Trees were then chipped (including bark) with a Morbark Chipper (Winn, MI) operated by Wood Preservers Inc., (Warsaw, VA) on 15 Apr. 2006 . Wood chips $(2.5 \mathrm{~cm} \times$ $2.5 \mathrm{~cm} \times 0.5 \mathrm{~cm}$ ) were further ground in a hammer mill (Meadows Mills, Inc., North Wilkesboro, NC) on 17 May 2006 to pass through a 4.76-mm screen. Pine tree substrate was used fresh (uncomposted) and amended with $0.6 \mathrm{~kg} \cdot \mathrm{m}^{-3}$ calcium sulfate $\left(\mathrm{CaSO}_{4}\right)$ based on previous work by Saunders et al. (2005) that showed improved plant growth when $\mathrm{CaSO}_{4}$ was incorporated in PTS. The $\mathrm{C} / \mathrm{N}$ ratio of PTS was reported to be 500:1 and 50:1 for PB by Jackson et al. (2008a), which was based on analysis conducted from substrate samples from batches similar to those used in this study. Samples of PTS were tested for $\mathrm{pH}$ before potting and not amended with lime as a result of the relatively high $\mathrm{pH}(\approx 5.8)$ observed, which has been shown previously in freshly ground pine wood (Wright et al., 2008a). Pine bark was preplant-amended with dolomitic lime at a rate of $3.6 \mathrm{~kg} \cdot \mathrm{m}^{-3}$ and $\mathrm{CaSO}_{4}$ at a rate of $0.6 \mathrm{~kg} \cdot \mathrm{m}^{-3}$ to increase the substrate $\mathrm{pH}$ to 5.5, which was similar to that of the PTS. Osmocote Plus (15N-3.9P-10K; O.M. Scott Horticulture Products, Marysville, $\mathrm{OH}$ ) was preplant incorporated in PB and PTS at rates of 4.2 or $8.4 \mathrm{~kg} \cdot \mathrm{m}^{-3}$. 
On 5 June 2006, cotoneaster (Cotoneaster horizontalis Decne. var. perpusillus C. K. Schneid.) liners $\left(10 \mathrm{~cm}\right.$ tall in $64-\mathrm{cm}^{3}$ containers) were potted in 15-L plastic containers [28 cm (high) $\times 30 \mathrm{~cm}$ (deep)] containing either PTS or PB. Three liners were evenly spaced and planted along the container edges, leaving the center of the container open. Additional containers were also filled separately with each of the two substrates and left fallow to compare changes in substrate shrinkage and physical properties with and without plants. Fallow containers were managed similarly as the containers with plants for the duration of the study. Aside from shrinkage and physical properties, no other data were recorded on fallow containers, but instead only on containers with plants, which is more representative of actual production practices. A $10.2 \mathrm{~cm}$ diameter $\times 5.1 \mathrm{~cm}$ high thinwalled polyvinyl chloride (PVC) collar was inserted $0.5 \mathrm{~cm}$ into the center of all containers, which served as a cradle for a soil $\mathrm{CO}_{2}$ flux chamber to be inserted and positioned securely above the substrate surface for $\mathrm{CO}_{2}$ efflux measurements. These collars minimize soil surface disturbance during $\mathrm{CO}_{2}$ measurements and reduce the sudden flux of $\mathrm{CO}_{2}$ associated with soil disturbance (Wang et al., 2005). Collars remained in the containers for the duration of the experiment without disturbance. Cotoneaster was used because of its weeping growth habit, which assured growth over the sides of the containers with minimal obstruction of the PVC collars. Plants in all containers were equally pruned throughout the study and plant growth was not recorded or analyzed. Containers were placed on a gravel nursery pad at the Urban Horticulture Center, Blacksburg, VA, and overhead irrigated daily (or as needed depending on weather conditions) to supply $1.3 \mathrm{~cm}$ water, respectively. The amount of water applied was determined based on the $\mathrm{CC}$ of the substrates (which was similar for both substrates) and the amount needed to achieve an approximate $20 \%$ leaching fraction. The municipal water source (Blacksburg, VA) for the Urban Horticulture Center had an alkalinity of $5.8 \mathrm{mEq} \cdot \mathrm{L}^{-1}$ and $\mathrm{pH} 6.8$.

Substrate solution was extracted using the pourthrough method (Wright, 1986) 1 week after potting (WAP) and then once per month through Oct. 2006 and analyzed for $\mathrm{pH}$ and electrical conductivity using a Hanna HI 9811 instrument (Hanna Instruments, Woonsocket, RI). Substrate solutions were frozen and later analyzed for $\mathrm{NO}_{3}-\mathrm{N}$ with an Orion ion selective electrode (Thermo Electron, Beverly, MA) on 17 Nov. 2007 and P and potassium $(\mathrm{K})$ concentrations on 28 Nov. 2007 with a Spectro Ciros Vision ICP (Spectro Analytical Instrument, Mahwah, NJ). On 8 Nov. 2006 containers were moved to a white polyethylene (poly) covered hoop house and placed pot-to-pot for overwintering. Containers were removed on $25 \mathrm{Apr}$. 2007, placed back on the outdoor gravel nursery pad, and fertilized (top-dressed) with the same fertilizer rates mentioned previously. Pourthroughs were conducted each month beginning in May and ending in September in 2007. Substrate shrinkage (in centimeters) was determined by measuring the difference in substrate height (from the top of the containers to the substrate surface in three locations in each container) at $1 \mathrm{WAP}$ and again at 70 WAP. Final measurements (70 WAP) for shrinkage determination were not made on fallow PB containers at either of the fertilizer rates and therefore are not reported in the results.

As a measure of active microbial activity in PB and PTS, substrate $\mathrm{CO}_{2}$ efflux levels were determined as an indicator/estimate of microbial activity, which will increase the potential for $\mathrm{N}$ immobilization to occur (Qui et al., 2008; Wang et al., 2003). Substrate $\mathrm{CO}_{2}$ efflux $\left(\mu \mathrm{mol} \mathrm{CO}_{2} / \mathrm{m}^{-2} \cdot \mathrm{s}^{-1}\right)$ was determined 1 WAP followed by every 4 weeks through October on six container replications of both substrates at each fertilizer rate using a LI-COR 6400 infrared gas analyzer (LICOR, Lincoln, NE) fitted with a LI-COR 6400-09 soil $\mathrm{CO}_{2}$ flux chamber. The soil chamber was designed to take nondestructive $\mathrm{CO}_{2}$ measurements from the substrate-filled containers. The LI-COR was recalibrated before each sampling date and the system was zeroed between treatment replications. The LICOR target value was set close to the ambient $\mathrm{CO}_{2}$ concentration $\left(\approx 380 \mu \mathrm{mol} \cdot \mathrm{mol}^{-1}\right)$, and the $\Delta \mathrm{CO}_{2}$ value was set as the factory default value $\left(10 \mu \mathrm{mol} \cdot \mathrm{mol}^{-1}\right.$; Li-Cor, 1997). Substrate $\mathrm{CO}_{2}$ efflux rates were measured on the same containers and at approximately the same time of day for each sampling date. Substrate $\mathrm{CO}_{2}$ efflux levels in this study are reported as the total $\mathrm{CO}_{2}$ released from the containers (at each measurement date only) with no separation made between the percentage released by plant roots or microbes. Substrate $\mathrm{CO}_{2}$ efflux data in this study were used as comparison between PB and PTS, not as an absolute measurement of carbon released.

For substrate physical properties and particle size determination, 20-L samples of all substrates were collected on 5 June 2006 when plants were potted. These substrates were taken from the same source used to pot this experiment and therefore amended similarly. Substrate samples were air-dried for $2 \mathrm{~d}$ then bagged and dry-stored for the duration of the experiment ( 70 weeks). At $70 \mathrm{WAP}$, samples from: 1) storage; 2) containers with plants (with roots manually removed by separating the root balls and gently shaking the substrate from the roots); and from 3 ) fallow containers were moistened to $50 \%$ moisture content (typical potting moisture content) and prepared for physical property and particle size determination. Analysis of the substrates that were in containers for 70 weeks (with plants or from fallow containers) were determined as an indicator of how the breakdown/decomposition of the materials changed physical properties over time compared with how they were initially (at potting). The properties (AS, CC, $\mathrm{TP}, \mathrm{BD})$ of the 70-week-old substrates discussed in this article are not representative of the physical conditions in the containers after 70 weeks under production conditions.
Physical properties, including AS, CC, $\mathrm{TP}$, and $\mathrm{BD}$, were determined on three replicate samples of each substrate using the NCSU Porometer method as described by Fonteno et al. (1995). Particle size distribution of $150 \mathrm{~g}$ oven-dried substrate samples were determined with 14 sieves (ranging from greater than $6.3 \mathrm{~mm}$ to less than $0.06 \mathrm{~mm}$ ) plus a bottom pan (Table 1). Sieves and pan were shaken for 10 min with a RX-29 Ro-Tap sieve shaker (278 oscillations/min, 150 taps/min; W.S. Tyler, Mentor, $\mathrm{OH}$ ), and the particle fractions retained on each sieve and the amount that passed through the smallest sieve and retained by the sieve pan were weighed.

The experimental design was completely randomized with two substrates, two planting methods (with and without plants), two fertilizer rates, and six replications per treatment for a total of 48 containers. Multiple comparison of means at $\alpha=0.05$ were made with Duncan's multiple range test and the analysis of variance (ANOVA) procedures of SAS (Version 9.1; SAS Institute, Inc., Cary, NC). Effect of substrate and fertilizer rate on substrate $\mathrm{CO}_{2}$ efflux was examined using PROC GLM repeated-measures ANOVA in SAS.

\section{Results and Discussion}

Particle size distribution: initial. Particle sizes were placed into texture groups of coarse $(2.0 \mathrm{~mm}$ or greater), medium (less than $2.0 \mathrm{~mm}$ to $0.5 \mathrm{~mm}$ or greater), and fine (less than $0.5 \mathrm{~mm}$ ). Pine bark had the highest percentage of coarse particles $(49.2 \%)$ at the beginning of the study (initial), whereas PTS had only $5 \%$ coarse particles (Table 1 ). Pine tree substrate had higher percentages of medium $(75.5 \%)$ and fine particles $(19.5 \%)$ compared with PB $(35.7 \%$ and $15.2 \%$, respectively) initially (Table 1 ).

Particle size distribution: final (data not available on pine bark in fallow containers so all 70 weeks after potting data represent pine bark in containers with plants present). Coarse PB particle percentage decreased at 70 WAP equally at both high and low fertilizer rates with plants (Table 1). The percentage of medium PB particles did not change after 70 weeks regardless of fertilizer rate $(38.5 \%$ and $38.8 \%)$ compared with the initial PB $(35.7 \%)$. The percentages of fine particles in $\mathrm{PB}$ were higher than the initial $\mathrm{PB}$ $(15.2 \%)$ and equal $(20.5 \%$ and $20.6 \%$, respectively) at both fertilizer rates (Table 1). The decrease in the amount of coarse particles and increase in the amount of fine particles is evidence of the decomposition/ breakdown in PB over the 70-week experiment (whether by microbial degradation or mechanical breakdown caused by plant roots).

Coarse PTS particle percentages decreased at 70 WAP at both high and low fertilizer rates and with or without (fallow) plants (Table 1). The percentage of medium PTS particles did not change from the initial PTS $(75.5 \%)$ in fallow containers regardless of fertilizer rate, but percentages decreased 
Table 1. Particle size distribution of pine bark (PB) and pine tree substrates (PTS) initially (at potting) and at 70 weeks after potting (WAP) in containers with plants when fertilized with $4.2(\mathrm{~L})$ or $8.4(\mathrm{H}) \mathrm{kg} \cdot \mathrm{m}^{-3}$ of Osmocote Plus $15 \mathrm{~N}-3.9 \mathrm{P}-10 \mathrm{~K}$ and maintained under outdoor nursery conditions. ${ }^{2, y}$

\begin{tabular}{|c|c|c|c|c|c|c|c|c|}
\hline \multirow[b]{3}{*}{ Sieve $(\mathrm{mm})^{\mathrm{x}}$} & \multicolumn{8}{|c|}{ Particle size distribution $(\%)^{\mathrm{z}}$} \\
\hline & & & & & & $\mathrm{AP}$ & & \\
\hline & PB & PTS $^{\mathrm{w}}$ & PTS-L & PTS-H & PB-L & PB-H & PTS-L & PTS-H \\
\hline $6.3-4.8$ & 8.3 & 1.0 & 0.0 & 0.0 & 6.4 & 8.0 & 0.0 & 0.0 \\
\hline $4.8-2.4$ & 25.5 & 1.4 & 0.7 & 1.5 & 23.9 & 20.4 & 1.0 & 1.7 \\
\hline $2.4-2.0$ & 4.9 & 2.6 & 1.4 & 0.7 & 5.6 & 5.5 & 1.6 & 0.6 \\
\hline $2.0-1.4$ & 10.9 & 10.4 & 16.1 & 16.2 & 12.3 & 8.7 & 12.3 & 22.3 \\
\hline $0.71-0.5$ & 7.7 & 15.8 & 10.1 & 7.1 & 8.8 & 9.5 & 12.0 & 6.7 \\
\hline $0.5-0.36$ & 3.3 & 6.3 & 9.6 & 11.0 & 4.8 & 4.6 & 14.6 & 11.3 \\
\hline $0.36-0.25$ & 3.5 & 4.4 & 4.5 & 4.4 & 2.8 & 4.5 & 6.2 & 4.9 \\
\hline $0.25-0.18$ & 3.6 & 3.3 & 4.5 & 5.9 & 2.4 & 2.3 & 4.5 & 6.9 \\
\hline $0.18-0.13$ & 1.6 & 3.3 & 2.7 & 2.7 & 4.7 & 3.8 & 2.8 & 2.7 \\
\hline $0.13-0.09$ & 1.3 & 1.4 & 2.4 & 1.3 & 3.2 & 2.0 & 1.4 & 1.7 \\
\hline Medium & $35.7 \mathrm{c}$ & $75.5 \mathrm{a}$ & $72.4 \mathrm{a}$ & $71.0 \mathrm{a}$ & $38.5 \mathrm{c}$ & $38.8 \mathrm{c}$ & $66.3 \mathrm{~b}$ & $65.8 \mathrm{~b}$ \\
\hline Fine & $15.2 \mathrm{~d}$ & $19.5 \mathrm{c}$ & $25.4 \mathrm{~b}$ & $26.7 \mathrm{~b}$ & $20.5 \mathrm{c}$ & $20.6 \mathrm{c}$ & $31.1 \mathrm{a}$ & $31.9 \mathrm{a}$ \\
\hline
\end{tabular}

${ }^{\mathrm{z}}$ Dry weight basis; values are means of three air-dried samples.

${ }^{y}$ Data are also reported for PTS in fallow containers at 70 WAP.

${ }^{\mathrm{x}} 1 \mathrm{~mm}=0.0394$ inch.

wPTS produced from 12-year-old loblolly pine trees harvested at ground level, delimbed, chipped, and hammer-milled to pass through a 4.76-mm screen.

vTexture grouping: coarse $=$ greater than $2.0 \mathrm{~mm}$; medium $=$ greater than 0.5 to less than $2.0 \mathrm{~mm}$; fine $=$ less than $0.5 \mathrm{~mm}$.

${ }^{u}$ Means within a row followed by the same letter are not significantly different based on Duncan's multiple range test $(P \leq 0.05, \mathrm{n}=3)$.

when plants were present for both fertilizer rates (Table 1). The percentage of fine PTS particles did not change from the initial $(19.5 \%)$ in fallow containers regardless of fertilizer rate, but percentages were higher when plants were present for both fertilizer rates $(31.1 \%$ and $31.9 \%$; Table 1$)$. The higher percentage of fine particles (and conversely, a lower percentage of medium particles) in PTS when plants were present indicates accelerated breakdown apparently resulting from the presence of plant roots. Plant root exudates have been widely reported to play an active role in enhancing microbial activity in soils (Davet, 2004), which likely explains the increased breakdown of PTS resulting from increased microbial populations in containers with plants.

Substrate physical properties: initial. Total porosity was higher in PTS $(91.2 \%)$ and above the recommended range $(50 \%$ to $85 \%$; Yeager et al., 2007) at the beginning of the study (initial) compared with PB (83.2\%; Table 2). Air space was higher in PTS $(35.9 \%)$ and also above the recommended range (10\% to $30 \%)$ at the beginning of the study than PB (26.4\%), which was within the suggested range. Container capacity was equal in PB and PTS initially (56.8\% and $55.3 \%$; Table 2). Bulk density was lower in PTS than PB initially, and both were below the recommended range (0.19 to 0.70$)$. Previous studies have shown that PTS can have $\mathrm{CC}$ percentages within the recommended range (and often equal to $\mathrm{PB}$ ) but have higher AS percentages than PB (Boyer, 2008; Wright and Browder, 2005; Wright et al., $2008 \mathrm{~b}$ ). In addition to these similar properties between PB and PTS, research has shown that PTS can have equal CC to peat substrates and still have higher AS (Jackson et al., 2008b; Saunders et al., 2006).

Substrate physical properties: final (data not available on pine bark in fallow containers so all 70 weeks after potting data represent pine bark in containers with plants present). Total porosity was unchanged in PB at 70 WAP compared with the initial TP and was unaffected by either the high or low fertilizer rate (Table 2). Air space percentages were lower in PB at 70 WAP than initially, but percentages remained within the recommended range and were unaffected by either fertilizer rate (Table 2). Inversely, CC and BD of $\mathrm{PB}$ increased at $70 \mathrm{WAP}$ and were equal at both fertilizer rates.

Total porosity was unchanged in PTS at $70 \mathrm{WAP}$ and was equal at both high and low fertilizer rates and with and without (fallow) plants (Table 2). Total porosity of fallow PTS at both fertilizer rates was similar to PB, whereas PTS with plants at both fertilizer rates had higher TP. Air space percentages decreased at 70 WAP in PTS with and without plants and at both fertilizer rates and remained higher than PB (Table 2). Container capacity increased at 70 WAP in PTS with and without plants and at both fertilizer rates and was equal to $\mathrm{PB}$ with the exception of the PTS with plants at the low fertilizer rate (Table 2). Bulk density remained lower in all PTS treatments than PB but remained within the recommended range (Table 2).

Shrinkage after 70 weeks was highest in fallow PTS at both fertilizer rates $(22.3 \%$ and $24.4 \%$ ), but shrinkage in PTS that contained plants was equal to PB with plants (Table 2). Shrinkage results from particle size breakdown (microbial decomposition) and sub- strate settling (finer particles fit between larger particles) caused by gravity and water movement through the substrate during irrigations (Bilderback and Lorscheider, 1995; Bures et al., 1993; Nash and Pokorny, 1990). Substrate shrinkage causes a decrease in AS and an increase in CC over time as observed in this study (Table 2) and reported in other works (Bohne and Gunther, 1997; Prasad and Chualain, 2005). Less shrinkage in PTS with plants in the containers compared with fallow PTS is likely a result of the plant roots that filled the voids created by decomposition and prevented substrate/root ball shrinkage.

Further work is needed to assess the actual in-container physical properties of PTS during crop production. Determining substrate physical properties without altering/disturbing the density or geometry of the substrate in containers will be more informative of the conditions experienced by plants during production. In this work, the substrate was removed from containers and physical properties were then determined.

Substrate solution $\mathrm{pH}$ and electrical conductivity (from containers with plants). Substrate solution $\mathrm{pH}$ was higher in PTS at both fertilizer rates compared with $\mathrm{PB}$ and decreased as fertilizer rate increased at all measuring dates in 2006 (Table 3). Substrate solution $\mathrm{pH}$ in PTS decreased one unit over the course of the sampling dates at each fertilizer rate in 2006 but remained higher than the $\mathrm{pH}$ of PB. Substrate solution electrical conductivity (EC) values were higher at the higher fertilizer rate in both substrates (Table 3). EC levels were higher in PB than in PTS at both fertilizer rates and at all measuring dates (Table 3), showing that higher rates of fertilizer are required for PTS compared 
Table 2. Physical properties of pine bark (PB) and pine tree substrates (PTS) initially (at potting) and at 70 weeks after potting (WAP) in containers with plants when fertilized with $4.2(\mathrm{~L})$ and $8.4(\mathrm{H}) \mathrm{kg} \cdot \mathrm{m}^{-3}$ of Osmocote Plus $15 \mathrm{~N}-3.9 \mathrm{P}-10 \mathrm{~K}$ and maintained under outdoor nursery conditions. ${ }^{2, y}$

\begin{tabular}{|c|c|c|c|c|c|}
\hline Substrates & $\begin{array}{l}\text { Total porosity } \\
\text { (\% vol) }\end{array}$ & $\begin{array}{l}\text { Air space }{ }^{\mathrm{w}} \\
(\% \mathrm{vol})\end{array}$ & $\begin{array}{c}\text { Container capacity } \\
(\% \text { vol })\end{array}$ & $\begin{array}{l}\text { Bulk density } \\
\left(\mathrm{g} \cdot \mathrm{cm}^{-3}\right)\end{array}$ & $\begin{array}{c}\text { Substrate } \\
\text { shrinkage }^{t}(\%)\end{array}$ \\
\hline \multicolumn{6}{|l|}{$\overline{\text { Initial (at potting) }}$} \\
\hline PB initial & $83.2 \mathrm{~b}^{\mathrm{s}}$ & $26.4 \mathrm{c}$ & $56.8 \mathrm{c}$ & $0.18 \mathrm{~b}$ & - \\
\hline PTS initial ${ }^{\mathrm{r}}$ & $91.2 \mathrm{a}$ & $35.9 \mathrm{a}$ & $55.3 \mathrm{c}$ & $0.14 \mathrm{~d}$ & - \\
\hline PB-L w/plant & $83.3 \mathrm{~b}$ & $19.7 \mathrm{~d}$ & $63.6 \mathrm{a}$ & $0.21 \mathrm{a}$ & $16.3 \mathrm{~b}$ \\
\hline PB-H w/plant & $83.8 \mathrm{~b}$ & $20.9 \mathrm{~d}$ & $62.9 \mathrm{a}$ & $0.22 \mathrm{a}$ & $16.7 \mathrm{~b}$ \\
\hline PTS-L w/plant & $89.2 \mathrm{a}$ & $29.3 \mathrm{~b}$ & $59.9 \mathrm{~b}$ & $0.16 \mathrm{c}$ & $17.4 \mathrm{~b}$ \\
\hline PTS-H fallow & $86.1 \mathrm{ab}$ & $25.1 \mathrm{c}$ & $61.0 \mathrm{ab}$ & $0.18 \mathrm{~b}$ & $24.4 \mathrm{a}$ \\
\hline Range $^{\mathrm{q}}$ & $50-85$ & $10-30$ & $45-65$ & $0.19-0.70$ & - \\
\hline
\end{tabular}

${ }^{2}$ Data were collected from three samples per substrate and represented as means. Analysis performed using the North Carolina State University Porometer method (Fonteno et al., 1995).

${ }^{y}$ Data are also reported for PTS in fallow containers at 70 WAP.

${ }^{\mathrm{x}}$ Total porosity is equal to container capacity + air space.

wAir space is the volume of water drained from the sample $\div$ volume of the sample.

${ }^{\mathrm{v}}$ Container capacity is (wet weight - oven dry weight) $\div$ volume of the sample.

"Bulk density after forced-air drying at $105^{\circ} \mathrm{C}$ for $48 \mathrm{~h}$.

'Shrinkage $=$ substrate height in container at $1 \mathrm{WAP}-$ substrate height at $70 \mathrm{WAP}$

${ }^{\text {s}}$ Means separated within columns using Duncan's multiple range test $(P \leq 0.05 ; \mathrm{n}=3)$.

rPTS produced from 12-year-old loblolly pine trees harvested at ground level, delimbed, chipped, and hammer-milled to pass through a 4.76-mm screen.

${ }^{\mathrm{q}}$ Suggested range for container substrates = Best Management Practices recommended sufficiency ranges for physical properties of substrates used in general container production (Yeager et al., 2007).

Table 3. Substrate solution pH and electrical conductivity (EC) sampled in 2006 and 2007 from pine bark (PB) or pine tree substrate (PTS) in containers with plants when fertilized with two rates of Osmocote Plus $15 \mathrm{~N}-3.9 \mathrm{P}-10 \mathrm{~K} .^{\mathrm{z}}$

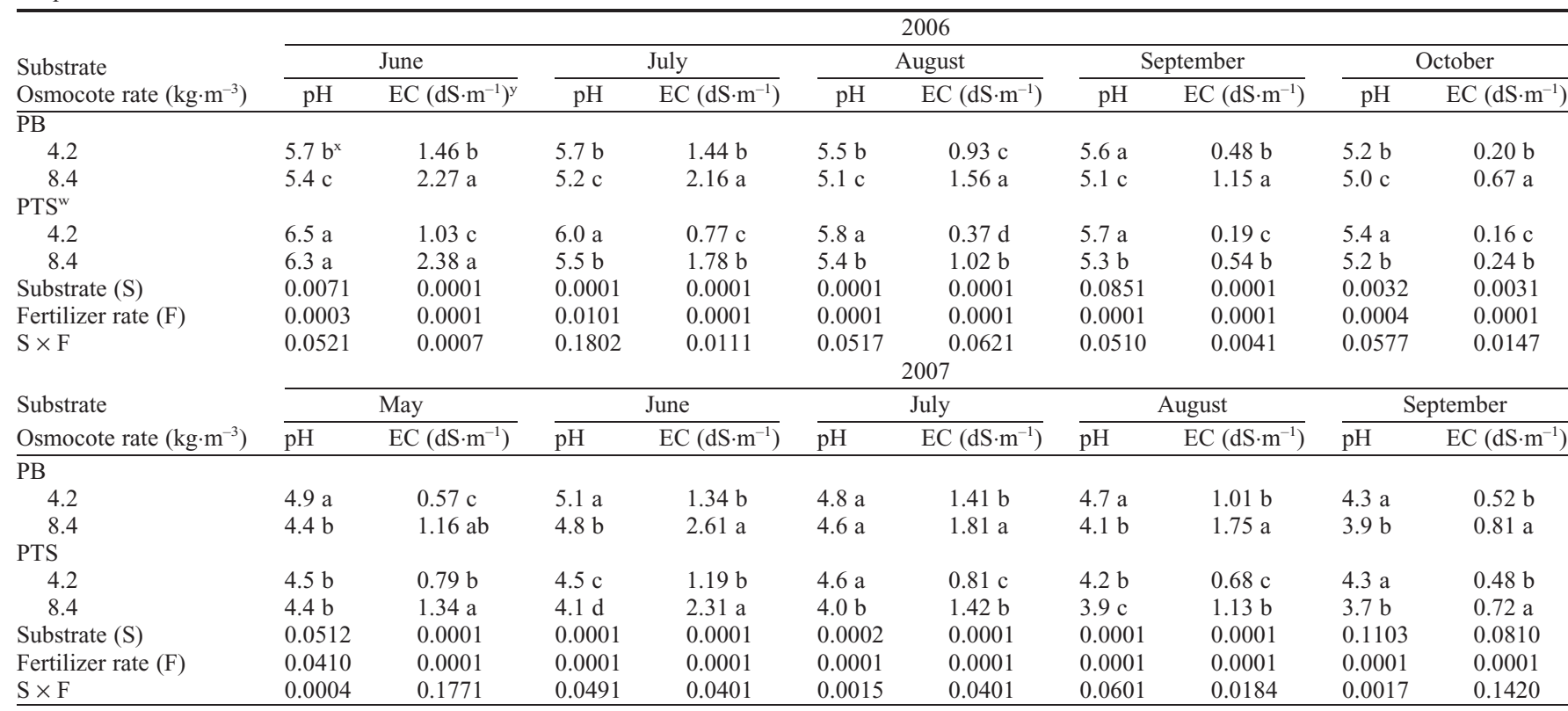

${ }^{\mathrm{z}} \mathrm{pH}$ and EC of substrate solution obtained by the pourthrough method (Wright, 1986).

${ }_{1} 1 \mathrm{dS} \cdot \mathrm{m}^{-1}=1 \mathrm{mmho} / \mathrm{cm}$

${ }^{x}$ Means separated within columns using Duncan's multiple range test $(P \leq 0.05 ; \mathrm{n}=4)$.

wPTS produced from12-year-old loblolly pine trees harvested at ground level, delimbed, chipped, and hammer-milled to pass through a 4.76-mm screen.

with PB to achieve comparable EC levels. Lower substrate EC (and substrate solution nutrients) and higher $\mathrm{pH}$ levels in PTS compared with $\mathrm{PB}$ have been previously reported by Boyer (2008), Jackson et al. (2008a), and Wright et al. (2006). Substrate solution EC values fell below the recommended range for nursery crops (0.5 to $1.0 \mathrm{dS} \cdot \mathrm{m}^{-1}$; Yeager et al., 2007) in PTS at the low fertilizer rate $\left(4.2 \mathrm{~kg} \cdot \mathrm{m}^{-3}\right)$ in August, whereas PB EC levels at the low fertilizer rate did not fall below recommended levels until Sept. 2006 (Table 3). Substrate solution EC at the higher fertilizer rate $\left(8.4 \mathrm{~kg} \cdot \mathrm{m}^{-3}\right)$, which is recommended for woody plant production (Jackson et al., 2008a), remained within recommended levels until October (Table 3). In 2007, substrate solution $\mathrm{pH}$ levels were lower in PTS than PB at both fertilizer rates and the levels decreased as fertilizer rate increased (Table 3). The lower $\mathrm{pH}$ in 2007 was a continuation of the trend of decreasing $\mathrm{pH}$, which was observed in 2006 over the course of the summer months. The $\mathrm{pH}$ decline observed in PTS could potentially be a concern during long-term production and may require adjusting (increasing) depending on the crop (species) grown. Substrate solution EC levels generally remained higher in PB than in PTS at both fertilizer rates with the exception of the May sampling date (Table 3). In contrast to 2006, during 2007, the substrate solution EC vales remained at or above the recommended range through all sampling dates in PTS at both the low and high fertilizer rates. Solution EC values were within or above the recommended levels for both fertilizer rates in $\mathrm{PB}$ (Table 3). 
Substrate nutrient availability (from containers with plants). Similar to the EC levels previously discussed, $\mathrm{NO}_{3}-\mathrm{N}$ concentrations were higher in $\mathrm{PB}$ at both fertilizer rates compared with PTS in 2006 (Table 4). Nitrate $\mathrm{N}$ levels in substrate solution were below recommended levels ( 15 to $25 \mathrm{mg} \cdot \mathrm{L}^{-1}$ ) in PTS beginning in July at the low fertilizer rate and also then in September for the high fertilizer rate (Table 4). Substrate solution $\mathrm{P}$ levels were equal in PB and PTS in 2006 with the one exception being at the low fertilizer rate in June when P levels were higher in PB (Table 4). All P concentrations were within or above the recommended level $\left(5\right.$ to $10 \mathrm{mg} \cdot \mathrm{L}^{-1}$ ) in both substrates at both fertilizer rates during all sample months in 2006 (Table 4). Substrate solution $\mathrm{K}$ concentrations were more often higher in PB than PTS at each fertilizer rate and at each sampling date in 2006 with a few exceptions when concentrations were equal in both substrates (Table 4), which is consistent with work published by Jackson et al. (2008a) and Wright et al. (2006). In contrast, PTS has been reported to have higher substrate solution $\mathrm{K}$ concentrations than peat substrates in the production of herbaceous crops (Jackson et al., 2008b; Wright et al., 2008a). Potassium concentrations were within or above recommended levels ( 10 to $20 \mathrm{mg} \cdot \mathrm{L}^{-1}$ ) in PB and PTS at both fertilizer rates at all sampling dates in 2006 with the exception of
PTS at the low fertilizer rate in September (Table 4).

In general, the same trend was present in 2007 in that most all nutrient concentrations were higher in PB than in PTS at both fertilizer rates. Nutrient concentrations in both substrates at both fertilizer rates were within or above recommended ranges (as shown previously) in 2007 with the exception of the low fertilizer rate for both PB and PTS, which both fell below the range in August and September, which was also observed in 2006 (Table 5).

Lower substrate solution $\mathrm{NO}_{3}-\mathrm{N}$ concentrations in PTS compared with PB over two growing seasons suggests that $\mathrm{NO}_{3}-\mathrm{N}$ is possibly being immobilized in the container substrate and not excessively leaching (in irrigation runoff) as once hypothesized by these authors (Brian Jackson and Robert Wright) as a reason for lower substrate solution EC levels in PTS even when applying high rates of fertilizer. Jackson and Wright (2007, 2009) and Jackson et al. (2009) have reported increased microbial activity and higher rates of $\mathrm{N}$ immobilization in PTS compared with PB and peat. The reason for generally lower substrate solution $\mathrm{P}$ concentrations in PTS could likely be a result of microbial immobilization of $\mathrm{P}$, which occurs in wood-based substrates (Handreck, 1996), thus reducing the amount of soluble $\mathrm{P}$ in substrate solution.
Substrate $\mathrm{CO}_{2}$ efflux (from container with plants). Substrate $\mathrm{CO}_{2}$ efflux was higher in PTS than in PB at both fertilizer rates and at each measurement date in 2006 (Table 6). Similar to these data, higher substrate $\mathrm{CO}_{2}$ efflux has been previously reported in PTS compared with PB during crop production (Jackson and Wright, 2007; Jackson et al., 2008a). Substrate $\mathrm{CO}_{2}$ efflux was lower at the higher fertilizer rate in both substrates at each measuring date (Table 6), which has been previously reported in PTS by Jackson et al. (2008a, 2009). Substrate $\mathrm{CO}_{2}$ efflux levels decreased through the summer measuring dates but remained higher in PTS than in $\mathrm{PB}$ although the magnitude of difference was less by October (Table 6). Results were similar in 2007 with substrate $\mathrm{CO}_{2}$ efflux remaining higher in PTS than in $\mathrm{PB}$ at both fertilizer rates, but the $\mathrm{CO}_{2}$ efflux levels were noticeably lower in 2007 than in 2006 (Table 6 ) indicating lower microbial activity, possibly a result of less decomposition occurring in the more stable year-old substrates. The reduction in microbial respiration rates that we observed in response to increasing fertilizer rate is supported by several previous reports showing both long-term and shortterm reductions in microbial activity after fertilization (Gough and Seiler, 2004; Thirukkumaran and Parkinson, 2000). One possible explanation for this response

Table 4. Substrate solution concentrations of nitrate nitrogen $\left(\mathrm{NO}_{3}-\mathrm{N}\right)$, phosphorus $(\mathrm{P})$, and potassium $(\mathrm{K})$ collected in 2006 from pine bark $(\mathrm{PB})$ or pine tree substrate (PTS) in containers with plants when fertilized with two rates of Osmocote Plus $15 \mathrm{~N}-3.9 \mathrm{P}-10 \mathrm{~K}{ }^{\mathrm{z}}$

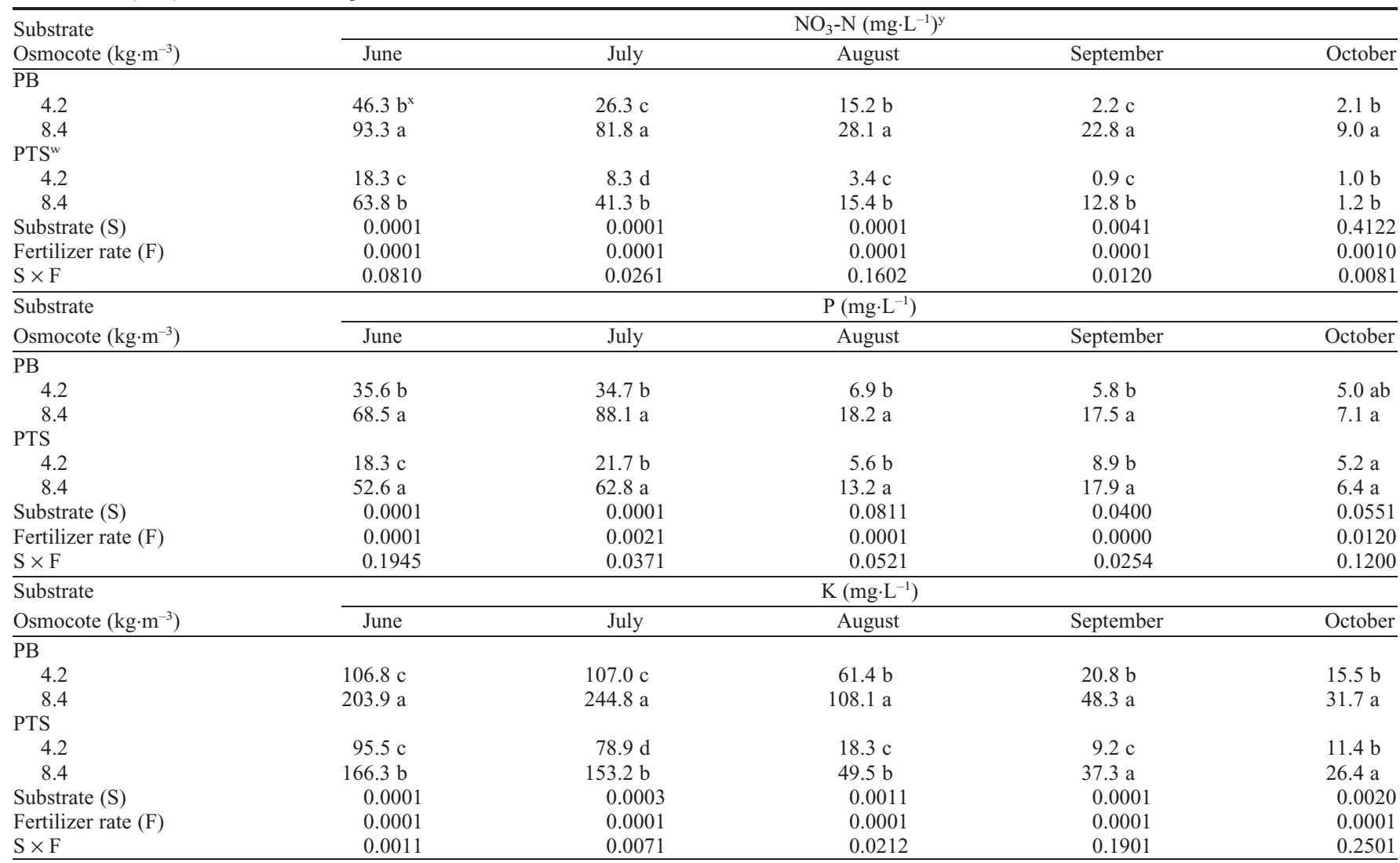

${ }^{\mathrm{z}}$ Substrate solution obtained by the pourthrough method (Wright, 1986).

${ }^{\mathrm{y}} 1 \mathrm{mg} \cdot \mathrm{L}^{-1}=1 \mathrm{ppm}$.

${ }^{\mathrm{x}}$ Means separated within columns by nutrient using Duncan's multiple range test $(P \leq 0.05 ; \mathrm{n}=4)$.

wPTS produced from12-year-old loblolly pine trees harvested at ground level, delimbed, chipped, and hammer-milled to pass through a 4.76 -mm screen. 
Table 5. Substrate solution concentrations of nitrate nitrogen $\left(\mathrm{NO}_{3}-\mathrm{N}\right)$, phosphorus $(\mathrm{P})$, and potassium $(\mathrm{K})$ collected in 2007 from pine bark $(\mathrm{PB})$ or pine tree substrate (PTS) in containers with plants when fertilized with two rates of Osmocote Plus $15 \mathrm{~N}-3.9 \mathrm{P}-10 \mathrm{~K} .^{\mathrm{z}}$

\begin{tabular}{|c|c|c|c|c|c|}
\hline \multirow{2}{*}{$\begin{array}{l}\text { Substrate } \\
\text { Osmocote }\left(\mathrm{kg} \cdot \mathrm{m}^{-3}\right)\end{array}$} & \multicolumn{5}{|c|}{$\mathrm{NO}_{3}-\mathrm{N}\left(\mathrm{mg} \cdot \mathrm{L}^{-1}\right)^{\mathrm{y}}$} \\
\hline & May & June & July & August & September \\
\hline \multicolumn{6}{|l|}{$\overline{\mathrm{PB}}$} \\
\hline 4.2 & $37.5 b^{x}$ & $30.5 \mathrm{~b}$ & $43.8 \mathrm{~b}$ & $11.1 \mathrm{~b}$ & $4.8 \mathrm{~b}$ \\
\hline 8.4 & $67.2 \mathrm{a}$ & $109.3 \mathrm{a}$ & $61.8 \mathrm{a}$ & $18.4 \mathrm{a}$ & $17.1 \mathrm{a}$ \\
\hline \multicolumn{6}{|l|}{$\mathrm{PTS}^{\mathrm{w}}$} \\
\hline 4.2 & $19.8 \mathrm{c}$ & $25.5 \mathrm{~b}$ & $31.9 \mathrm{c}$ & $6.0 \mathrm{~b}$ & $2.8 \mathrm{~b}$ \\
\hline 8.4 & $61.1 \mathrm{a}$ & $88.0 \mathrm{a}$ & $48.3 \mathrm{~b}$ & $19.8 \mathrm{a}$ & $16.3 \mathrm{a}$ \\
\hline Substrate (S) & 0.2110 & 0.0001 & 0.0001 & 0.0092 & 0.0480 \\
\hline Fertilizer rate $(\mathrm{F})$ & 0.0001 & 0.0001 & 0.0001 & 0.0001 & 0.0002 \\
\hline $\mathrm{S} \times \mathrm{F}$ & 0.0400 & 0.0005 & 0.0201 & 0.0028 & 0.0021 \\
\hline Substrate & \multicolumn{5}{|c|}{$\mathrm{P}\left(\mathrm{mg} \cdot \mathrm{L}^{-1}\right)$} \\
\hline Osmocote $\left(\mathrm{kg} \cdot \mathrm{m}^{-3}\right)$ & May & June & July & August & September \\
\hline \multicolumn{6}{|l|}{$\overline{\mathrm{PB}}$} \\
\hline 4.2 & $17.0 \mathrm{~b}$ & $34.4 \mathrm{~b}$ & $29.8 \mathrm{c}$ & $10.7 \mathrm{~b}$ & $7.5 \mathrm{~b}$ \\
\hline 8.4 & $28.0 \mathrm{a}$ & $56.1 \mathrm{a}$ & $64.7 \mathrm{a}$ & $24.5 \mathrm{a}$ & $19.5 \mathrm{a}$ \\
\hline \multicolumn{6}{|l|}{ PTS } \\
\hline 4.2 & $13.3 \mathrm{~b}$ & $28.3 \mathrm{~b}$ & $19.3 \mathrm{~d}$ & $12.4 \mathrm{~b}$ & $6.6 \mathrm{~b}$ \\
\hline 8.4 & $21.8 \mathrm{a}$ & $52.1 \mathrm{a}$ & $43.4 \mathrm{~b}$ & $25.3 \mathrm{a}$ & $15.6 \mathrm{a}$ \\
\hline Substrate (S) & 0.0004 & 0.0011 & 0.0621 & 0.0080 & 0.0004 \\
\hline Fertilizer rate $(\mathrm{F})$ & 0.0001 & 0.0001 & 0.0001 & 0.0001 & 0.0001 \\
\hline $\mathrm{S} \times \mathrm{F}$ & 0.0287 & 0.0008 & 0.0391 & 0.0100 & 0.0100 \\
\hline Substrate & \multicolumn{5}{|c|}{$\mathrm{K}\left(\mathrm{mg} \cdot \mathrm{L}^{-1}\right)$} \\
\hline Osmocote $\left(\mathrm{kg} \cdot \mathrm{m}^{-3}\right)$ & May & June & July & August & September \\
\hline \multicolumn{6}{|l|}{$\overline{\mathrm{PB}}$} \\
\hline 4.2 & $89.9 \mathrm{~b}$ & $169.7 \mathrm{~b}$ & $76.5 \mathrm{c}$ & $78.3 \mathrm{c}$ & $26.6 \mathrm{~b}$ \\
\hline 8.4 & $171.2 \mathrm{a}$ & $276.0 \mathrm{a}$ & $201.8 \mathrm{a}$ & $150.7 \mathrm{a}$ & $61.5 \mathrm{a}$ \\
\hline \multicolumn{6}{|l|}{ PTS } \\
\hline 4.2 & $65.4 \mathrm{~b}$ & $126.7 \mathrm{~b}$ & $80.5 \mathrm{c}$ & $47.8 \mathrm{~d}$ & $29.7 \mathrm{~b}$ \\
\hline 8.4 & $194.4 \mathrm{a}$ & $244.8 \mathrm{a}$ & $168.9 \mathrm{~b}$ & $115.7 \mathrm{~b}$ & $17.2 \mathrm{c}$ \\
\hline Substrate (S) & 0.0041 & 0.0001 & 0.0004 & 0.0001 & 0.0621 \\
\hline Fertilizer rate $(\mathrm{F})$ & 0.0001 & 0.0001 & 0.0001 & 0.0001 & 0.0001 \\
\hline$\underline{\mathrm{S} \times \mathrm{F}}$ & 0.0010 & 0.0017 & 0.1020 & 0.0022 & 0.0001 \\
\hline
\end{tabular}

${ }^{\mathrm{z}}$ Substrate solution obtained by the pourthrough method (Wright, 1986).

${ }^{\mathrm{y}} 1 \mathrm{mg} \cdot \mathrm{L}^{-1}=1 \mathrm{ppm}$.

${ }^{x}$ Means separated within columns by nutrient using Duncan's multiple range test $(P \leq 0.05 ; \mathrm{n}=4)$.

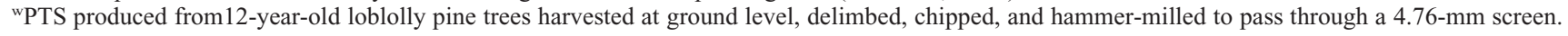

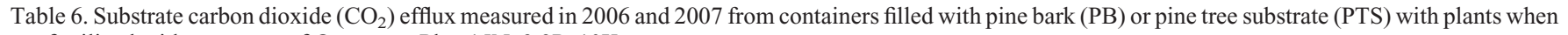
fertilized with two rates of Osmocote Plus $15 \mathrm{~N}-3.9 \mathrm{P}-10 \mathrm{~K} .^{\mathrm{z}}$

\begin{tabular}{|c|c|c|c|c|c|}
\hline \multirow{3}{*}{$\begin{array}{l}\text { Substrate } \\
\text { Osmocote }\left(\mathrm{kg} \cdot \mathrm{m}^{-3}\right)\end{array}$} & \multicolumn{5}{|c|}{2006} \\
\hline & \multicolumn{5}{|c|}{$\mathrm{CO}_{2}$ efflux $\left(\mu \mathrm{mol} \mathrm{CO} \mathrm{CO}_{2} / \mathrm{m}^{-2} \cdot \mathrm{s}^{-1}\right)$} \\
\hline & June & July & August & September & October \\
\hline \multicolumn{6}{|l|}{$\overline{\mathrm{PB}}$} \\
\hline 4.2 & $15.8 \mathrm{c}^{\mathrm{y}}$ & $10.9 \mathrm{c}$ & $5.7 \mathrm{c}$ & $7.0 \mathrm{c}$ & $3.5 \mathrm{~b}$ \\
\hline 8.4 & $12.5 \mathrm{~d}$ & $8.8 \mathrm{~d}$ & $5.5 \mathrm{c}$ & $5.8 \mathrm{~d}$ & $3.3 \mathrm{~b}$ \\
\hline \multicolumn{6}{|l|}{$\operatorname{PTS}^{x}$} \\
\hline 4.2 & $31.3 \mathrm{a}$ & $22.1 \mathrm{a}$ & $19.9 \mathrm{a}$ & $20.3 \mathrm{a}$ & $11.1 \mathrm{a}$ \\
\hline 8.4 & $25.4 \mathrm{~b}$ & $18.3 \mathrm{~b}$ & $15.9 \mathrm{~b}$ & $16.8 \mathrm{~b}$ & $12.3 \mathrm{a}$ \\
\hline Substrate (S) & 0.0001 & 0.0031 & 0.0001 & 0.0007 & 0.0061 \\
\hline Fertilizer rate $(\mathrm{F})$ & 0.0120 & 0.0002 & 0.0814 & 0.0130 & 0.0370 \\
\hline $\mathrm{S} \times \mathrm{F}$ & 0.0230 & 0.0014 & 0.0120 & 0.0017 & 0.0002 \\
\hline & \multicolumn{5}{|c|}{2007} \\
\hline Substrate & \multicolumn{5}{|c|}{$\mathrm{CO}_{2}$ efflux $\left(\mu \mathrm{mol} \mathrm{CO}_{2} / \mathrm{m}^{-2} \cdot \mathrm{s}^{-1}\right)$} \\
\hline Osmocote $\left(\mathrm{kg} \cdot \mathrm{m}^{-3}\right)$ & May & June & July & August & September \\
\hline \multicolumn{6}{|l|}{$\overline{\mathrm{PB}}$} \\
\hline 4.2 & $3.2 \mathrm{c}$ & $8.7 \mathrm{c}$ & $7.2 \mathrm{~b}$ & $6.5 \mathrm{~b}$ & $5.5 \mathrm{c}$ \\
\hline 8.4 & $2.1 \mathrm{~d}$ & $5.2 \mathrm{~d}$ & $6.6 \mathrm{~b}$ & $5.7 \mathrm{c}$ & $2.8 \mathrm{~d}$ \\
\hline \multicolumn{6}{|l|}{ PTS } \\
\hline 4.2 & $9.5 \mathrm{a}$ & $17.2 \mathrm{a}$ & $14.0 \mathrm{a}$ & $11.8 \mathrm{a}$ & $12.1 \mathrm{a}$ \\
\hline 8.4 & $7.1 \mathrm{~b}$ & $14.3 \mathrm{~b}$ & $15.6 \mathrm{a}$ & $11.7 \mathrm{a}$ & $9.0 \mathrm{~b}$ \\
\hline Substrate (S) & 0.0071 & 0.0030 & 0.0025 & 0.0082 & 0.0081 \\
\hline Fertilizer rate $(\mathrm{F})$ & 0.1038 & 0.0190 & 0.0672 & 0.2310 & 0.0120 \\
\hline $\mathrm{S} \times \mathrm{F}$ & 0.0204 & 0.0320 & 0.0082 & 0.0505 & 0.0841 \\
\hline
\end{tabular}

${ }^{\mathrm{z}} \mathrm{CO}_{2}$ efflux measured with a LI-COR 6400 infrared gas analyzer fitted with a LI-COR 6400-09 soil CO $\mathrm{CH}_{2}$ flux chamber $(\mathrm{n}=6)$.

${ }^{y}$ Means separated within columns using Duncan's multiple range test $(P \leq 0.05 ; \mathrm{n}=4)$.

xPTS produced from 12-year-old loblolly pine trees harvested at ground level, delimbed, chipped, and hammer-milled to pass through a 4.76-mm screen.

could be that increased salt concentration in the substrate may modify the microflora populations or reduce their activity (Allison, 1965).

\section{Conclusions}

This study demonstrates that PTS does decompose in containers under fertilized out- door nursery conditions as indicated by a reduction in substrate particle size and greater substrate shrinkage in fallow PTS containers over time. The reduction in particle size 
changed the physical properties (AS and CC) of PTS based on analysis conducted after 70 weeks, but like PB, the structure (physical properties) of PTS remained acceptable for plant growth. Substrate shrinkage in PTS would be a major concern if not for plant roots that apparently filled the voids caused by decomposition. Despite the decomposition, this study illustrates that the stability of PTS over two growing seasons (70 weeks) is sufficient to support plant growth. For longer-term production (more than 70 weeks), or production in warmer climates, decomposition may be more of a problem. However, it may be possible to minimize decomposition by using a coarser PTS (i.e., 16.0-mm up to 2.5 -cm particles) produced with larger hammer mill screens, which can then be amended with PB, sand, or other fine particle material to achieve the desired AS and WHC (Wright et al., 2008b).

The decrease in $\mathrm{pH}$ of PTS that was observed in this study may warrant $\mathrm{pH}$ adjustments depending on the crop being grown. Currently, the $\mathrm{pH}$ of PTS produced from fresh (recently harvested) pine wood is not adjusted (i.e., dolomitic lime additions) as a result of the desirable $\mathrm{pH}$ levels observed in short-term crop production, but based on results from this study, $\mathrm{pH}$ adjustments of PTS for long-term crop production may be necessary. The lower substrate solution EC levels reported in PTS at the end of Summer 2006 also deserve close attention when using PTS so that supplemental fertilizer applications (often supplied as a liquid fertilizer application) can be made in the late summer or fall to ensure adequate nutrient levels during that time.

\section{Literature Cited}

Aaron, J.R. 1982. Conifer bark: Its properties and uses. Forest Commun. Forest Rec. 110.

Allaire-Leung, S.E., J. Caron, and L.E. Parent. 1999. Changes in physical properties of peat substrates during plant growth. Can. J. Soil Sci. 79:137-139.

Allison, F.E. 1965. Decomposition of wood and bark sawdusts in soil, nitrogen requirements, and effects on plants. US Dept. Agr. Tech. Bull. No. 1332.

Bilderback, T.E. and M.R. Lorscheider. 1995. Physical properties of double-processed pine bark: Effects on rooting. Acta Hort. 401:77-83.

Bilderback, T.E., S.L. Warren, J.S. Owen, Jr., and J.P. Albano. 2005. Healthy substrates need physicals too! HortTechnology 15:747-751.

Blagodatsky, S.A., O. Heinemeyer, and J. Richter. 2000. Estimating the active and total soil microbial biomass by kinetic respiration analysis. Biol. Fertil. Soils 32:73-81.

Bodman, K. and K.V. Sharman. 1993. Container media management. Queensland DPI, Queensland Nursery Industry Association, Brisbane, Australia.

Bohne, H. 2004. Growth of nursery crops in peatreduced and in peat-free substrates. Acta Hort. 644:103-106.

Bohne, H. and C. Gunther. 1997. Physical properties of peat determined with different methods. Acta Hort. 450:271-276.

Bollen, W.B. and D.W. Glennie. 1961. Sawdust, bark, and other wood wastes for soil conditioning and mulching. Forest Prod. J. 11:38-46.
Boyer, C.R. 2008. Evaluation of clean chip residual as an alternative substrate for container-grown plants, Auburn Univ., Auburn, AL. PhD Diss.

Boyer, C.R., G.B. Fain, C.H. Gilliam, T.V. Gallagher, H.A. Torbert, and J.L. Sibley. 2008. Clean chip residual: A substrate component for growing annuals. HortTechnology 18:423-432.

Broschat, T.K. 1995. Nitrate, phosphate, and potassium leaching from container-grown plants fertilized by several methods. HortScience 30:74-77.

Brown, O.D.R. and E.R. Emino. 1981. Response of container-grown plants to six consumer growing media. HortScience 16:78-80.

Bruckner, U. 1997. Physical properties of different potting media and substrate mixtures - especially air-and water capacity. Acta Hort 450:263-270.

Bugbee, G.J. and G.C. Elliott. 1998. Leaching of nitrogen and phosphorus from potting media containing biosolids compost as affected by organic and clay amendments. Bull. Environ. Contam. Toxicol. 60:716-723.

Bures, S., F.A. Pokorny, D.P. Landau, M.A. Farmer, and A.M. Ferrenberg. 1993. Shrinkage, porosity characterization, and computer simulation of horticultural substrates. Acta Hort. 342:229-234.

Casadesus, J., R. Caceres, and O. Marfa. 2007. Dynamics of $\mathrm{CO}_{2}$ efflux from the substrate root system of container-grown plants associated with irrigation cycles. Plant Soil 300:71-82.

Davet, P. 2004. Microbial ecology of the soil and plant growth. Scientific Publishing, Enfield, $\mathrm{NH}$.

Ding, W., Y. Cai, Z. Cai, K. Yagi, and X. Zheng. 2007. Soil respiration under maize crops: Effect of water, temperature, and nitrogen fertilization. Soil Sci. Soc. Amer. J. 71:944951.

Drzal, M.S., W.C. Fonteno, and K.D. Cassel. 1999. Pore fraction analysis: A new tool for substrate testing. Acta Hort. 481:43-54.

Environmental Protection Agency. 2006. National primary drinking water regulations. 15 Sept. 2008. $<$ http://www.epa.gov/safewater/dwh/c-ioc/ nitrates.html>.

Fain, G.B., C.H. Gilliam, J.L. Sibley, and C.R. Boyer. 2008a. Wholetree substrates derived from three species of pine in production of annual vinca. HortTechnology 18:13-17.

Fain, G.B., C.H. Gilliam, J.L. Sibley, C.R. Boyer, and A.L. Walker. 2008b. Wholetree substrate and fertilizer rate in production of greenhousegrown petunia (Petunia $\times$ hybrida Vilm.) and marigold (Tagetes patula L.). HortScience 43:700-705.

Fischer, P., E. Meinken, and F. Kalthoff. 1993. Holzfaserstoffe im test. (Woodfibre in test). Gärtnerbörse Gartenwelt 26:1220-1222.

Fog, K. 1988. The effect of added nitrogen on the rate of decomposition or organic matter. Biol. Rev. Camb. Philos. Soc. 63:433-462.

Fonteno, W.C., C.T. Hardin, and J.P. Brewster. 1995. Procedures for determining physical properties of horticultural substrates using the NCSU Porometer. Horticultural Substrates Laboratory. North Carolina State University, Raleigh, NC.

Gagnon, B. and R.R. Simard. 1999. Nitrogen and phosphorus release from on-farm and industrial composts. Can. J. Soil Sci. 79:481-489.

Gough, C.M. and J.R. Seiler. 2004. Belowground carbon dynamics in loblolly pine (Pinus taeda) immediately following diammonium phosphate fertilization. Tree Physiol. 24:845-851.

Handreck, K.A. 1992a. Rapid assessment of the rate of nitrogen immobilization in organic components of potting media. I. Method development. Commun. Soil Sci. Plant Anal. 23:201215.

Handreck, K.A. 1992b. Rapid assessment of the rate of nitrogen immobilization in organic components of potting media. II. Nitrogen drawdown index and plant growth. Commun. Soil Sci. Plant Anal. 23:217-230.

Handreck, K.A. 1996. Phosphorus immobilization in wood waste-based potting media. Commun. Soil Sci. Plant Anal. 27:2295-2314.

Hart, M.R., B.F. Quin, and M.L. Nguyen. 2004. Phosphorus runoff from agricultural land and direct fertilizer effects: A review. J. Environ. Qual. 33:1954-1972.

Hoitink, H.A. and H.A. Poole. 1979. Mass production of composted tree barks for container media. Ohio Flor. Assn. Bull. 599:3-4.

Jackson, B.E. 2008. Chemical, physical, and biological factors influencing nutrient availability and plant growth in a pine tree substrate. Virginia Polytechnic Institute \& State Univ., Blacksburg, VA. PhD Diss.

Jackson, B.E. and R.D. Wright. 2007. Pine tree substrate: Fertility requirements. Proc. Southern Nursery Assoc. Research Conf. 52:58-61.

Jackson, B.E. and R.D. Wright. 2009. Pine tree substrate: An alternative and renewable growing media for horticulture crop production. Acta Hort. 819:265-272.

Jackson, B.E., R.D. Wright, and M.M. Alley. 2009. Comparison of fertilizer nitrogen availability, nitrogen immobilization, substrate carbon dioxide efflux, and nutrient leaching in peat-lite, pine bark, and pine tree substrates. HortScience. 44:781-790.

Jackson, B.E., R.D. Wright, J.F. Browder, J.R. Harris, and A.X. Niemiera. 2008a. Effect of fertilizer rate on growth of azalea and holly in pine bark and pine tree substrates. HortScience 43:1561-1568.

Jackson, B.E., R.D. Wright, and M.C. Barnes. 2008 b. Pine tree substrate, nitrogen rate, particle size, and peat amendment affects poinsettia growth and substrate physical properties. HortScience 43:2155-2161.

Kenna, S.W. and C.E. Whitcomb. 1985. Hardwood chips as an alternative medium for container plant production. HortScience 20:867-869.

Laiche, A.J., Jr. and V.E. Nash. 1986. Evaluation of pine bark, pine bark with wood, and pine tree chips as components of a container plant growing media. J. Environ. Hort. 4:22-25.

Lemaire, F. 1995. Physical, chemical, and biological properties of growing medium. Acta Hort. 396:273-284.

Lemaire, F., A. Dartigues, and L.M. Riviere. 1989. Physical and chemical characteristics of lignocellulosic material. Acta Hort. 238:9-15.

LiCor. 1997. 6400-09 Soil CO2 flux chamber instruction manual. LiCor, Lincoln, NE.

Meinken, E. and P. Fischer. 1997. Sackungsverhalten von Holzfasern. Gärtnerbörse 9:494-496.

Nash, M.A. and F.A. Pokorny. 1990. Shrinkage of selected two-component container media. HortScience 25:930-931.

Nash, V.E. and A.J. Laiche. 1981. Changes in the characteristics of potting media with time. Commun. Soil Sci. Plant Anal. 12:1011-1020.

Needelman, B.A., M.M. Wander, and G.S. Shi. 2001. Organic carbon extraction efficiency in chloroform fumigated and non-fumigated soils. Soil Sci. Soc. Amer. J. 65:1731-1733.

Prasad, M. and D.N. Chualain. 2005. Relationship between particle size and air space of growing media. Acta Hort. 648:161-166.

Qui, S., A.J. McComb, and R.W. Bell. 2008. Ratios of $\mathrm{C}, \mathrm{N}$, and $\mathrm{P}$ in soil water direct microbial 
immobilization-mineralization and $\mathrm{N}$ availability in nutrient amended sandy soils in southwestern Australia. Agr. Ecosyst. Environ. 127:93-99.

Richards, D., M. Lane, and D.V. Beardsell. 1986. The influence of particle-size distribution in pinebark:sand:brown coal potting mixes on water supply, aeration, and plant growth. Scientia Hort. 29:1-14.

Riviere, L.M. and C. Milhau. 1983. The use of wood waste composts in the making of substrates for container crops. Acta Hort. 150:475-489.

Saunders, T., J.F. Browder, B.E. Jackson, and R.D. Wright. 2006. Particle size of a pine chips substrate affects plant growth. Proc. Southern Nursery Assoc. Research Conf. 51:46-48.

Saunders, T.N., R.D. Wright, and J.F. Browder. 2005. Chipped pine logs: A potential substrate for nursery and greenhouse crops. Proc. Southern Nursery Assn. Res. Conf. 50:112-114.

Sharman, K.V. and K. Bodman. 1991. Wood wastes affect fertilizer performance. Aust. Hort. 89:30-32.

Steinweg, J.M., A.F. Plante, R.T. Conant, E.A. Paul, and D.L. Tanaka. 2008. Patterns of substrate utilization during long-term incubations at different temperatures. Soil Biol. Biochem. 40:2722-2728.
Thirukkumaran, C.M. and D. Parkinson. 2000. Microbial respiration, biomass, metabolic quotient and litter decomposition in a lodgepole pine forest amended with nitrogen and phosphorus fertilizers. Soil Biol. Biochem. 32:59-66.

Turner, C.P. and W.R. Carlile. 1983. Microbial activity in blocking composts. 1 . Measurement of $\mathrm{CO}_{2}$ evolution and $\mathrm{O}_{2}$ consumption. Acta Hort. 150:75-81.

Wang, W.J., R.C. Dalal, P.W. Moody, and C.J. Smith. 2003. Relationships of soil respiration to microbial biomass, substrate availability and clay content. Soil Biol. Biochem. 35:273-284.

Wang, W.J., Y.G. Zu, H.M. Wang, T. Hirano, K. Takagi, K. Sasa, and T. Koike. 2005. Effect of collar insertion on soil respiration in a larch forest measured with a LI-6400 soil $\mathrm{CO}_{2}$ flux system. J. For. Res. 10:57-60.

Wright, R.D. 1986. The pour-through nutrient extraction method procedure. HortScience 21:227-229.

Wright, R.D. and J.F. Browder. 2005. Chipped pine logs: A potential substrate for greenhouse and nursery crops. HortScience 40:1513-1515.

Wright, R.D., J.F. Browder, and B.E. Jackson. 2006. Ground pine chips as a substrate for container-grown woody nursery crops. J. Environ. Hort. 24:181-184.

Wright, R.D., B.E. Jackson, J.F. Browder, and J.G. Latimer. 2008a. Growth of chrysanthemum in ground pine trees requires additional fertilizer. HortTechnology 18:111-115.

Wright, R.D., B.E. Jackson, and M.C. Barnes. 2008b. Pine tree substrate construction for optimal water holding capacity and air space. Proc. Southern Nursery Assoc. Research Conf. 53:52-54.

Yeager, T.H., D.C. Fare, J. Lea-Cox, J. Ruter, T.E. Bilderback, C.H. Gilliam, A.X. Niemiera, S.L. Warren, T.E. Whitwell, R.D. Wright, and K.M. Tilt. 2007. Best management practices: Guide for producing container-grown plants. 2nd Ed. Southern Nurserymen's Assoc., Marietta, GA.

Yeager, T.H. and R.D. Wright. 1982. Phosphorus requirement of Ilex crenata Thumb. Cv. Helleri grown in a pine bark medium. J. Amer. Soc. Hort. Sci. 107:558-562.

Yeager, T.H., R.D. Wright, D. Fare, C.H. Gilliam, J.R. Johnson, T.E. Bilderback, and R. Zondag. 1993. Six state survey of container nursery nitrate nitrogen runoff. J. Environ. Hort 11:206-208. 